\title{
Critical care management of systemic mastocytosis: when every wasp is a killer bee
}

\author{
Hinke Y. van der Weide ${ }^{1}$, David J. van Westerloo ${ }^{2}$ and Walter M. van den Bergh ${ }^{1 *}$
}

\begin{abstract}
Since the critical care physician will most likely be involved in a life-threatening expression of systemic mastocytosis, recognition of this disease is of utmost importance in the critical care management of these patients. Mastocytosis is a severely under-recognized disease because it typically occurs secondary to another condition and thus may occur more frequently than assumed. In this article, we will review the current knowledge on the treatment of mastocytosis crises with an emphasis on critical care management. Mastocytosis is characterized by the clonal proliferation and accumulation of mast cells in different tissues. Mast cell mediators contain a wide range of biologically active substances that may lead to itching and hives but may ultimately lead to anaphylactic shock caused by the release of histamine and other mediators from mast cells. The mainstay of therapy is the avoidance of potential triggers of mast cell degranulation and, if unsuccessful, blocking the cascade of mast cell mediators. The critical care physician should be well aware of the special precautions which should be kept in mind throughout the management of a mastocytosis crisis to avoid massive mast cell degranulation. Histamine-releasing drugs and certain physical triggers like temperature change should be avoided.
\end{abstract}

\section{Introduction}

Mastocytosis is characterized by the clonal proliferation and accumulation of mast cells in different tissues, with a preferential localization in the skin and bone marrow. The clinical presentation of mastocytosis is heterogeneous, ranging from skin-limited to a more aggressive systemic variant [1]. Mast cells produce and release a large number of different mediators, which are either released

\footnotetext{
* Correspondence: w.m.van.den.bergh@umcg.nl

${ }^{1}$ Department of Critical Care, University Medical Center Groningen, University of Groningen, Hanzeplein 1, 9700 RB Groningen, The Netherlands Full list of author information is available at the end of the article
}

continuously or stored in granules and released after stimulation (Table 1). Signs and symptoms are caused by release of these mast cell mediators or local accumulation of mast cells $[2,3]$. The disease may be undiagnosed until patients are exposed to elicitors of mast cell degranulation leading to severe anaphylactic reactions and even death [4-7]. Anaphylaxis may be the result of a variety of triggers. Several case reports described anaphylaxis following regional or general anaesthesia as the first presentation of mastocytosis $[8,9]$. The diagnosis may be difficult as anaphylaxis may develop with a delay of hours [10]. Furthermore, drugs that are known potential mast cell elicitors are frequently used pharmaceuticals in the ICU [9]. Physicians should therefore realise that adjustment of management to avoid trigger application is necessary in order to prevent further endangerment of vital functions. However, owing to the low but probably under-reported prevalence of the disease, most critical care physicians are not familiar with the management of the patient with mastocytosis. In the following sections, we review the pathogenesis and prophylactic measures of mast cell mediator release, with an emphasis on critical care management.

\section{Mastocytosis}

\section{Incidence and prevalence}

The incidence of mastocytosis has been estimated to be between 1:1,000 and 2:100,000, but several cases are not recognized as caused by mastocytosis $[2,11]$. The prevalence of mastocytosis was recently studied in the adult population of the Groningen region in The Netherlands and appeared to be at least 13 cases per 100,000 inhabitants [12].

\section{Pathophysiology}

Mast cells develop from pluripotent stem cells in the bone marrow and spleen. In mastocytosis, the majority of cases are associated with gain-of-function point mutations of KIT, a tyrosine kinase receptor located on mast cells. As a consequence, the receptor is continuously activated, 
Table 1 Effects of mast cell mediators in mastocytosis

\begin{tabular}{|c|c|}
\hline Mediator(s) & Features \\
\hline \multicolumn{2}{|l|}{ Cardiovascular } \\
\hline Prostaglandins & Flushing (increased heart rate and increased cardiac output) \\
\hline Protease (Chymase) & Increased blood pressure \\
\hline Histamine & Increased vasopermeability \\
\hline Histamine, prostaglandin $\mathrm{D}_{2}$, leukotrienes, and platelet-activating factor & Vasodilatation and hypotension \\
\hline Platelet-activating factor & Arrhythmia \\
\hline \multicolumn{2}{|l|}{ Cutaneous } \\
\hline Histamine, prostaglandin $D_{2}$, and platelet-activating factor & Urticaria with or without angioedema \\
\hline Histamine & Pruritus \\
\hline \multicolumn{2}{|l|}{ Respiratory } \\
\hline Histamine, leukotrienes, prostaglandin $D_{2}$, and platelet-activating factor & Bronchusconstriction \\
\hline Prostaglandin $\mathrm{D}_{2}$ and leukotrienes & Increased mucus production \\
\hline Platelet-activating factor and leukotrienes & Pulmonary oedema \\
\hline Histamine & Rhinitis \\
\hline \multicolumn{2}{|l|}{ Gastrointestinal } \\
\hline Histamine & Increased gastric acid secretion \\
\hline Histamine & Diarrhoea \\
\hline Platelet-activating factor & Abdominal ache \\
\hline \multicolumn{2}{|l|}{ Hematologic } \\
\hline Heparin and proteases & Coagulation disturbances \\
\hline \multicolumn{2}{|l|}{ Remainder } \\
\hline Histamine & Headache \\
\hline Heparin, interleukin-6 (IL-6), and tryptase & Osteopenia and osteoporosis \\
\hline $\begin{array}{l}\text { Pro-inflammatory cytokines (for example, tumour necrosis factor-alpha) and } \\
\text { chemokines }\end{array}$ & $\begin{array}{l}\text { Fatigue, weight loss, local inflammation, oedema } \\
\text { formation, and leukocyte migration }\end{array}$ \\
\hline Growth factor (IL-6) & Fever \\
\hline Tryptase & $\begin{array}{l}\text { Endothelial activation with consecutive inflammatory } \\
\text { reactions }\end{array}$ \\
\hline
\end{tabular}

leading to uncontrolled growth and activation of mast cells (Fig. 1) [2]. Mast cell progenitors are the only myeloid cells that exit the bone marrow before complete maturation. The destination of mast cells is beneath or in the epithelium, close to vessels, smooth muscle cells, and glandular tissue, where they act as outposts of the immune system against exogenous allergens and pathogens [2]. Subjects with mastocytosis can experience non-specific symptoms like generalized pruritus, flushing, diarrhoea, abdominal pain, anaphylaxis, and osteoporosis due to a release of mast cell mediators, weight loss, malabsorbtion, cytopenia, organomegaly, and bone pain and fracture due to infiltration of mast cells in organs in advanced or aggressive mastocytosis [1].

\section{Diagnosis and classification}

Mastocytosis is classified by the World Health Organization (WHO) in the category of 'myeloproliferative neoplasms' and can be subdivided into cutaneous and systemic mastocytosis and mast cell neoplasm (Table 2). To establish the diagnosis of systemic mastocytosis, either one major and two minor or three minor WHO criteria have to be fulfilled (Table 3). The indolent form is the most prevalent subtype of systemic mastocytosis [13]. An increased basal level of the mast cell mediator tryptase (more than $20 \mathrm{ng} / \mathrm{mL}$ ) in serum may indicate the presence of the disease [14]. When mastocytosis is suspected (for example, in a patient presenting with anaphylactic shock due to a wasp sting), a marked increased tryptase concentration is the hallmark of the diagnosis [1]. One can also expect to find coagulation disturbances, caused by the mast cell mediators heparin and protease, and (methyl)histamine in urine. In this particular example, immunoglobulin (Ig) against wasp-antigen (rVes v5) shall be positive, revealing an IgE-mediated reaction $[1,13,14]$. 


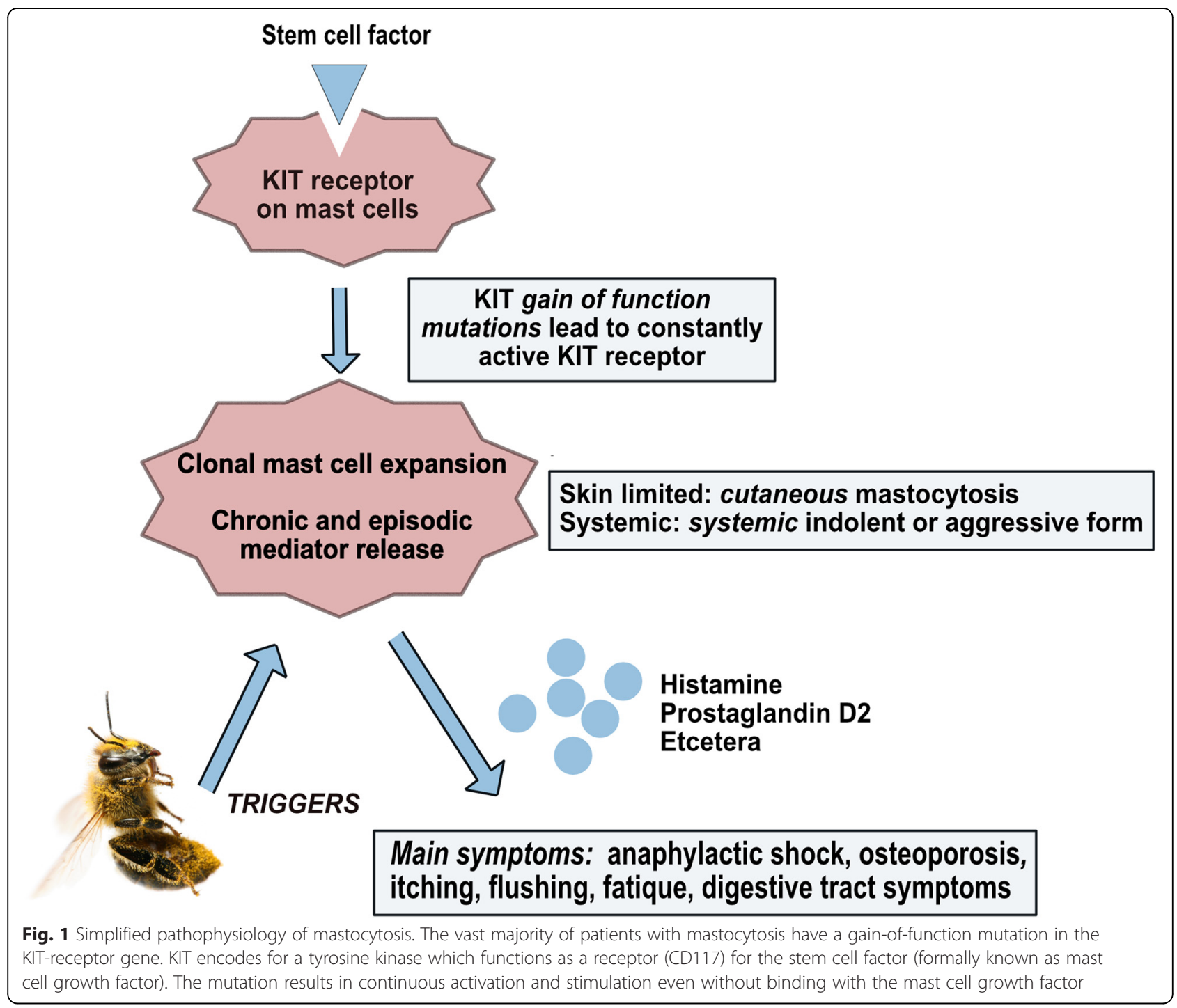

\section{Anaphylaxis and risk factors}

Stimulation of mediator release occurs by either IgE- or non-IgE-mediated mechanisms, including physical stimuli and drugs. The marked increased mediator release from the elevated mast cell numbers explains the much higher incidence as well as severity of anaphylaxis in mastocytosis patients as compared with the general population [3]. Symptoms appear to be more severe in patients with extensive systemic disease, which is reflected by a higher serum tryptase level [15]. A study that described the trigger factors for anaphylaxis in patients with mastocytosis found that the major precipitating agents were Hymenoptera (wasps, bees, ants, and flies) stings (27\%), foods (24\%), and medications (18\%) [15]. The prevalence of Hymenoptera venom allergy among patients with mastocytosis varies between $23 \%$ and $47 \%[11,12]$. Hymenoptera stings mostly cause severe anaphylactic reactions (grade III), whereas foods and medication lead to milder systemic reactions (grade II). However, fatal cases of drug hypersensitivity have been described in the literature $[7,8]$. Medications that are potential initiators of mastocyte degranulation on the basis of case reports and drugs associated with histamine release in general are listed in Table 4.

\section{Critical care management}

Anaphylactic shock and complications are related to mast cell degranulation; that is, spontaneous bleeding may present features of mastocytosis [6, 16]. When present, shock needs to be treated with the usual treatment, including the administration of epinephrine. For all patients with mastocytosis, epinephrine should be readily available as it hinders mast cell degranulation and is the first drug of choice during haemodynamic failure in these patients [7]. Haemorrhage with disturbed coagulation tests can be treated with protamin 
Table 2 World Health Organization classification of mastocytosis

\begin{tabular}{ll}
\hline Variant & Subvariants \\
\hline 1. Cutaneous mastocytosis & - Urticaria pigmentosa \\
& - Diffuse cutaneous mastocytosis \\
& - Mastocytoma of skin \\
2. Systemic mastocytosis & \\
Indolent systemic mastocytosis & - Smouldering systemic mastocytosis Isolated bone marrow mastocytosis \\
Aggressive systemic mastocytosis & - Lymphadenopathic systemic mastocytosis with eosinophilia \\
Systemic mastocytosis with an associated non-mast & - Systemic mastocytosis with myelodysplastic syndrome \\
cell lineage disorder & - Systemic mastocytosis with myeloproliferative disorder \\
& - Systemic mastocytosis with chronic myelomonocytic leukaemia \\
& - Systemic mastocytosis with non-Hodgkin's lymphoma \\
Mast cell leukaemia & - Systemic mastocytosis with hypereosinophilic syndrome \\
3. Mast cell neoplasms & - Aleukaemic mast cell leukaemia \\
Mast cell sarcoma & \\
\hline Extracutaneous mastocytoma & \\
\hline
\end{tabular}

and plasma coagulation factors to reverse the anticoagulant effects of heparin [9].

It is important to realise that, during further ICU treatment, patients with mastocytosis are inevitably exposed to triggers of mast cell degranulation, which may be followed by severe anaphylactic responses [10]. When a patient with known mastocytosis is admitted to the ICU, it may be helpful to make a risk profile to estimate the chance of developing anaphylactoid reactions. The risk profile includes the form of mastocytosis, the basal serum tryptase level as a marker of the total mast cell load, previous anaphylactic reactions, and present mast cell activation status comprising recent reactions to triggers. Histamine-releasing drugs, such as opioids and neuromuscular blocking agents, should be

Table 3 World Health Organization criteria for systemic mastocytosis

Major criterion

- The existence of 15 or more multifocal mast cell clusters in the bone marrow or in other tissue biopsies

Minor criteria

- Basal tryptase level of more than $20 \mathrm{ng} / \mathrm{mL}$

- Either (a) more than $25 \%$ of mast cells in infiltrates of bone marrow or other extracutaneous organs are atypical or spindle-shaped or (b) more than $25 \%$ of mast cells in bone marrow aspirate are immature or atypical.

- Co-expression of CD117 with CD25 or CD2 (or both) on mast cells

- Codon 816 mutation in the C-KIT gene

To establish the diagnosis of systemic mastocytosis, either one major and two minor or three minor World Health Organization criteria have to be fulfilled. Patients who have a history of mast cell activation symptoms without skin lesions but who do not fully meet diagnostic criteria for systemic mastocytosis are classified as having mast cell activation syndrome $[9,17]$ avoided (Table 4). Additionally, infusion of cold solutions, trauma, friction, and other mechanical factors are elicitors of mast cell degranulation and should be prevented. Also, several antibiotics and radio contrast materials are known activators of mast cells [9]. Even anxiety may trigger mast cell degranulation, for which benzodiazepines may be considered. Continuous infusion of medication and solutions theoretically leads to less release of mast cell mediators and is preferred over single boluses.

When (surgical) intervention is planned during ICU admission, precautions must be taken. The anaesthetist should be conscious of the potential triggers and consequences of mast cell degranulation and be informed about the risk profile of the patient. Pre-medication may include benzodiazepines, $\mathrm{H} 1$ - and H2-receptor antagonists to block the cascade of mast cell mediators, and glucocorticoids as anti-inflammatory and mast cell stabilizers. Because mast cell degranulation has been observed hours after trigger application, we recommend continuing medication for at least 4 hours after trigger application. Non-steroidal antiinflammatory drugs (NSAIDs) are effective prophylactic drugs because of their antiprostaglandin actions. However, they should be given only to patients who have received these drugs previously, as NSAIDs are also associated with serious anaphylactoid reactions [9].

\section{Conclusions}

Mastocytosis is a clonal disorder characterized by the proliferation and accumulation of mast cells in different tissues. After trigger application, an overwhelming release of mast cell mediators may lead to severe haemodynamic compromise and multi-organ failure. Knowledge of the 
Table 4 Medications which are known potential triggers of mast cell degranulation

\begin{tabular}{|c|c|c|c|c|c|}
\hline & Opioids & Hypnotics & Muscle relaxants & $\begin{array}{l}\text { (Local) } \\
\text { anaesthesia }\end{array}$ & Volatile anaesthetics \\
\hline \multirow[t]{2}{*}{ Avoid } & & & Mivacurium & \multirow[t]{2}{*}{ Nefopam } & \\
\hline & & & Atracurium & & \\
\hline $\begin{array}{l}\text { Avoid rapid perfusion } \\
\text { (if possible, use } \\
\text { alternative agents) }\end{array}$ & Morphine Codeine & Thiopental & $\begin{array}{l}\text { Succinylcholine } \\
\text { Rocuronium }\end{array}$ & Lidocain Bupivacain & \\
\hline \multirow[t]{2}{*}{ Low risk } & \multirow{2}{*}{$\begin{array}{l}\text { Fentanyl Sufentanil } \\
\text { Remifentanil Alfentanil }\end{array}$} & \multirow{2}{*}{$\begin{array}{l}\text { Midazolam Propofol } \\
\text { Etomidate Ketamine }\end{array}$} & \multirow{2}{*}{$\begin{array}{l}\text { Cis-atracurium } \\
\text { Pancuronium } \\
\text { Vecuronium }\end{array}$} & Ropivacain & \multirow{2}{*}{$\begin{array}{l}\text { Desfurane Sevofluran } \\
\text { Enflurane Isoflurane }\end{array}$} \\
\hline & & & & Paracetamol & \\
\hline
\end{tabular}

pathophysiology of the disease is of paramount importance for adequate treatment and the prevention of secondary events of mast cell degranulation due to mechanical or pharmacological triggers. During treatment, physicians should avoid potential triggers of mast cell degranulation, consider giving pre-medication before interventions, and be aware of and prepared for the clinical manifestations caused by mast cell mediators. Avoiding medication and physical stimuli that trigger histamine release and blocking the cascade of actions of mast cells constitute the mainstay of therapy besides treatment of anaphylaxis.

\section{Abbreviations}

Ig: Immunoglobulin; NSAID: Non-steroidal anti-inflammatory drug; WHO: World Health Organization.

\section{Competing interests}

The authors declare that they have no competing interests.

\section{Authors' contributions}

All authors participated in the design and coordination of the review, helped to draft the manuscript, and read and approved the final version.

\section{Author details}

${ }^{1}$ Department of Critical Care, University Medical Center Groningen, University of Groningen, Hanzeplein 1, 9700 RB Groningen, The Netherlands. ${ }^{2}$ Department of Intensive Care, Leiden University Medical Center, Albinusdreef 2, 2333 ZA Leiden, The Netherlands.

Published online: 03 June 2015

\section{References}

1. Valent P, Akin C, Arock M, Brockow K, Butterfield JH, Carter MC, et al. Definitions, criteria and global classification of mast cell disorders with special reference to mast cell activation syndromes: a consensus proposal. Int Arch Allergy Immunol. 2012;157:215-25.

2. Andersen $C L$, Kristensen $T K$, Severinsen MT, Møller MB, Vestergaard $H$, Bergmann OJ, et al. Systemic mastocytosis - a systematic review. Dan Med J. 2012;59:A439.

3. Müller UR, Haeberli G. The problem of anaphylaxis and mastocytosis. Curr Allergy Asthma Rep. 2009;9:64-70.

4. Reiter N, Reiter M, Altrichter S, Becker S, Kristensen T, Broesby-Olsen S, et al. Anaphylaxis caused by mosquito allergy in systemic mastocytosis. Lancet. 2013;382:1380.

5. Geerlings SE, Canning-v Dijk MR. A patient resuscitated after an insect sting. A clinical pathological conference. Neth J Med. 2001;58:45-51.

6. Kors JW, van Doormaal JJ, de Monchy JG. Anaphylactic shock following Hymenoptera sting as a presenting symptom of systemic mastocytosis. J Intern Med. 1993;233:255-8.

7. Vaughan ST, Jones GN. Systemic mastocytosis presenting as profound cardiovascular collapse during anaesthesia. Anaesthesia. 1998;53:804-9.
8. Yunaev M, Hughes TM, Abdul-Razak M. Systemic mastocytosis and surgery a potential disaster. ANZ J Surg. 2010;80:860-1.

9. Brockow K, Bonadonna P. Drug allergy in mast cell disease. Curr Opin Allergy Clin Immunol. 2012;12:354-60

10. Konrad FM, Schroeder TH. Anaesthesia in patients with mastocytosis. Acta Anaesthesiol Scand. 2009;53:270-1.

11. Konrad FM, Unertl KE, Schroeder TH. Provocation of mastocytosis in anaesthesia. Anaesthesist. 2009;58:1239-43.

12. van Doormaal JJ, Arends S, Brunekreeft KL, van der Wal VB, Sietsma J, van Voorst Vader PC, et al. Prevalence of indolent systemic mastocytosis in a Dutch region. J Allergy Clin Immunol. 2013;131:1429-30.

13. van Anrooij B, van der Veer E, de Monchy JG, van der Heide S, Kluin-Nelemans JC, van Voorst Vader PC, et al. Higher mast cell load decreases the risk of Hymenoptera venom induced anaphylaxis in patients with mastocytosis. J Allergy Clin Immunol. 2013;132:132.

14. Bonadonna P, Zanotti R, Pagani M, Caruso B, Perbellini O, Colarossi S, et al. How much specific is the association between hymenoptera venom allergy and mastocytosis? Allergy. 2009;64:1379-82.

15. Brockow K, Jofer C, Behrendt H, Ring J. Anaphylaxis in patients with mastocytosis: a study on history, clinical features and risk factors in 120 patients. Allergy. 2008;63:226-32.

16. Koenig M, Morel J, Reynaud J, Varvat C, Cathébras P. An unusual cause of spontaneous bleeding in the intensive care unit - mastocytosis: a case report. Cases J. 2008;1:100.

17. Afrin LB. The presentation, diagnosis and treatment of mast cell activation syndrome. Curr Allergy Clin Immunol. 2014;27:146-60. 